\title{
EDITORIAL
}

\section{Moving toward a gene therapy for Huntington's disease}

\author{
Gene Therapy (2015) 22, 931-933; doi:10.1038/gt.2015.102
}

\section{GENE THERAPY}

Gene therapy has recently undergone a renaissance with renewed expectation that transfer of genetic information to diseased cells will restore function. Gene therapy for highly diverse, rare metabolic diseases appears promising where single gene defects predict a disease phenotype that can be corrected by the addition of the wild-type (wt) gene. Genetic interventions in neurodegenerative diseases (NDs) affecting the brain, however, face added complexities that include: (i) late stage onset of clinical signs of disease where considerable neuronal loss and damage to nonneuronal cell types such as glia has already occurred, (ii) widespread degenerative processes suggesting that more global vector delivery will likely be needed for long-term effective treatment and (iii) symptoms that often affect specific brain activities and pathways, necessitating targeted gene delivery to specific neuronal or glial subtypes. Although early disease diagnosis would provide the opportunity to intervene prior to clinical symptoms, the genetic basis underlying several prevalent NDs (for example, Parkinson's disease) is complex and not fully understood so that early identification of individuals at risk is difficult.

\section{POLYQ EXPANSION}

NDs caused by polyglutamine (polyQ) expansion represent an important group because early diagnosis exists. ${ }^{1}$ These diseases lead to mutant protein aggregate accumulation that not only blocks critical protein function but also acquires a destructive gain of function that contributes to the disease phenotype. As such, these diseases are autosomal dominant and elimination of the root cause requires knock out or knock down of the mutant gene or product. Although gene repair (restoration of the normal number of glutamine (CAG) codons) is the most desirable option, this template-dependent strategy is not yet practical in vivo. Moreover, both gene repair and targeted gene inactivation methods using such tools as CRISPR-Cas9 have an associated risk of creating off-target mutations and their reduced efficiency in non-dividing cells poses a challenge. A gene repressor strategy using viral vectors has been developed for Huntington's disease (HD) using engineered zinc finger fusion proteins specific for the CAG repeat of the mutant Huntingtin gene to effectively and selectively inhibit transcription of the expanded allele. ${ }^{2,3}$ Other efforts over the past decade have focused on using singlenucleotide polymorphisms (SNPs) linked to the CAG expansion to selectively target mutant gene mRNA for degradation or reduced translation (see below).

\section{HUNTINGTON'S DISEASE}

$\mathrm{HD}$ is a neurodegenerative disorder affecting 30000 Americans. It is characterized by chorea, dystonia, psychiatric and cognitive abnormalities and dementia occurring sometime during mid-life, progressing inexorably to death $10-20$ years following onset. ${ }^{4,5}$ A polyQ expansion in the Huntingtin gene $(H T T)$ exceeding $\sim 40$ copies within the amino-terminal region of the Huntingtin protein
(HTT) causes abnormal folding and accumulation of mutant protein aggregates in cytoplasmic/neuropil inclusions and in the nuclei of cells in both the central nervous system and peripheral tissues. $^{6,7}$ The pathology of HD involves the prevalent loss of efferent medium spiny neurons (MSNs) in the striatum (caudate nucleus and putamen) of the basal ganglia, ${ }^{8}$ as well as more widespread degeneration throughout the cortex and ultimately the hippocampus., ${ }^{9,10}$ The HD pathology is thought to result mostly from gain-of-function toxicity of the mutant (mu) HTT protein that is accompanied by broad-based neuronal transcriptome dysregulation, significant alterations in the synaptic properties of multiple neuronal cell types in the basal ganglia and extensive alterations in the circuitry encompassing the corticostriatal-thalamic loops. ${ }^{6,11,12}$ Mutant HTT also directly inhibits mitochondrial protein import resulting in mitochondrial dysfunction and lowering the threshold for caspase activation. ${ }^{13}$ Fulllength wt HTT, found primarily within the cytoplasm, is crucial for survival of specific MSNs within the striatum due to its antiapoptotic activity and important role in maintaining the proper functional status of neurons. ${ }^{14}$ Currently there is no treatment for $H D$, although genetic therapy appears possible and may be the most potentially effective intervention, particularly if delivered early in the disease course.

\section{MOUSE MODELS}

A major advance in studying $\mathrm{HD}$ has been the development of genetic mouse models that exploit the mutation underlying HD and mimic some of the clinical and neuropathological phenomena observed in HD patients. ${ }^{15,16}$ These model systems generally have highly extended CAG repeats in order to accelerate the disease phenotype. However, the human disease typically involves fewer repeats and the onset is more insidious with abundant neurodegeneration, which is lacking in the rodent models. Nevertheless, these models provide an opportunity to test HD gene therapy approaches. Both viral and non-viral gene transfer have been exploited as potential therapies for HD. A number of approaches have been tested, including vector delivery of genes encoding neurotrophic factors to enhance interneuron survival, muHTT mRNA (SNP)-specific microRNAs and single hairpin RNAs to block formation of the mutant protein, and most recently, allele-specific blockage of transcription elongation. ${ }^{2,3} \mathrm{~A}$ variety of viral vectors have been used for gene delivery, predominantly vectors derived from adenovirus, ${ }^{17,18}$ adeno-associated virus $^{2,3,19-25}$ and lentivirus. ${ }^{26}$ In addition, multiple studies have been performed with directly administered antisense oligonucleotides (ASOs), small interfering $\mathrm{RNAs}^{27-30}$ and aggregate-specific antibodies. $^{31,32}$

\section{RESTORATION OF WT FUNCTION}

Although there are a number of potential gene therapy strategies, knock-out of the mutant $H T T$ gene using a vector-expressed editing tool that distinguishes between the mutant and wt allele is currently the most attractive option for treatment of HD by gene therapy. However, allele-selective mutant gene knockout is challenging, as the mutant gene differs from the wt allele only in the number of CAG repeat codons aside from an occasional linked SNP. Thus both alleles will be vulnerable, necessitating complementation with an editing-resistant (for example, codon- 
modified) copy of the gene. To our knowledge, this two-pronged strategy has not thus far been attempted. The $H T T$ gene is large ( 9.4 kb complementary DNA), clearly exceeding the capacity of most currently developed viral vector systems. In addition, codelivery of muHTT editing tools can only be assured by expression from the same vector, further raising the demands on the vector payload capacity. Choosing the best vector system to pursue treatment of HD will likely involve a combination of considerations that include safety data in patients, vector capacity, tropism, mode of delivery, vector distribution (including the ability to spread broadly through microtubule mediated transport in afferent cells) and sensitivity to anti-viral immunity. AAV and replicationdefective, helper-independent herpes simplex virus (HSV) represent two extremes in payload capacity, that is, $\sim 4.5 \mathrm{~kb}$ versus $25-$ $30 \mathrm{~kb}$, but both virus systems have favorable safety data in clinical trials. AAV has been used to deliver neurotrophic factors to patients with ND (for example, Parkinson's Disease) whereas HSV vector introduction into the central nervous system has thus far been limited to the treatment of brain tumors. AAV has favorable distribution data in animal models, including evidence of serotype-dependent transcyctosis through the blood brain barrier, albeit at low efficiency, ${ }^{33}$ and both viruses can be axonally transported along nerve fiber tracks in brain; ${ }^{34-36}$ axonal transport could allow vector targeting to cortical neurons affected in HD. For example, vector injection into different brain regions such as caudate/putamen should allow axonal transport to cortical/ thalamic and substantia nigral regions. In this way, specific and functionally related brain areas can be targeted. Although both AAV and HSV can move in both a retrograde and anterograde direction, HSV is more efficient, requiring orders of magnitude fewer viral particles to accomplish equal transduction. AAV delivery can be enhanced by magnetic resonance imagingguided delivery using advanced cannula, and under pressure, methods that are untested with HSV vectors but should work in a similar manner. The two vector systems differ substantially in sensitivity to immune-mediated inhibition of transduction, AAV being quite sensitive whereas HSV is effectively delivered to brain tumors despite pre-existing immunity. HSV reactivates from latency despite high neutralizing antibody titers, which has thwarted vaccine development. ${ }^{38}$ Intrathecal AAV vector delivery has the advantage of avoiding toxicity related to vector accumulation in peripheral organs, but might allow transduction of only a limited percentage of brain cells in rodents and primates; ${ }^{39}$ the efficiency is likely to differ depending on the serotype used.

Although HSV vectors have previously suffered from toxicity and loss of transgene expression, recent vector designs suggest that these issues can be overcome. ${ }^{40}$ In particular, after functional deletion of all of the immediate early genes, resulting in complete transcriptional silencing of all viral genes, we have identified specific sites in the viral genome that protect inserted non-viral promoters against epigenetic silencing in neurons and thereby allow sustained transgene expression in rodent brains (G Verlengia, M Simonato, Y Miyagawa and J Glorioso, unpublished). These highly defective viruses can be propagated in engineered cells that complement critical replication functions in trans. In addition to high capacity, HSV offers other attractive features. These include full retargeting of virus infection and transduction of particular brain cell types, and ongoing efforts in our laboratory are attempting to design HSV vectors capable of transcytosis by retargeting the viral envelope for interaction with transcytosis receptors. Transgenes can be further controlled by combining specific promoter-enhancers with cellular microRNAbinding sites engineered into the transgene mRNA to exquisitely control the regulation of transgene expression at multiple levels. ${ }^{41}$ Although an 'ideal' delivery tool for gene therapy of HD is still under development, it appears likely that such vehicles will become available in the near term. It seems clear that the ideal vector should have the space to accommodate multiple transgenes, such as CRISPR/Cas9 and editing-resistant HTT. Furthermore, the ideal vector should be amenable to targeting of various affected cell types in different brain areas and should be able to provide temporary transcription of editing genes for inactivation of muHTT while allowing continued expression of the wt allele or vector-based homolog.

\section{CLINICAL TRIALS}

Beyond vector selection, clinical trial design will require pharmacodynamic and disease progression biomarkers to measure disease amelioration. Considerable progress is being made in this area, installing confidence that successful therapy can be monitored by analyses of cerebrospinal fluid and blood including the measurement of spinal fluid biomarkers of axonal transport activity ${ }^{42}$ and magnetic resonance spectroscopy to evaluate metabolic markers of neurodegeneration. ${ }^{43,44}$ The first gene therapy clinical trial is now underway (ISIS Pharmaceuticals Inc., Carlsbad, CA, USA) using chemically modified ASOs that do not distinguish between mutant and wt HTT mRNA. These compounds are administered intrathecally, which limits their distribution, and they must be given chronically, requiring repeated hospital visits. Nonetheless, this development represents an important first step in the translation of laboratory findings into clinical practice. New vector designs will likely provide the opportunity to create permanent muHTT gene knockout and replacement therapy, paving the way for broad application to other polyQ-related NDs. Indeed, it may be anticipated that the next generation of therapies to emerge will involve one or more of these nascent approaches.

\section{CONFLICT OF INTEREST}

Dr JCG is a founder of Nuvovec srl and Switch Bio LLC. The remaining authors declare no conflict of interest.

JC Glorioso ${ }^{1}$, JB Cohen ${ }^{1}$, DL Carlisle ${ }^{2}$, I Munoz-Sanjuan ${ }^{3}$ and RM Friedlander ${ }^{2}$

${ }^{1}$ Department of Microbiology and Molecular Genetics, The University of Pittsburgh School of Medicine, Pittsburgh, PA, USA;

${ }^{2}$ Department of Neurological Surgery, The University of Pittsburgh School of Medicine, Pittsburgh, PA, USA and

${ }^{3} \mathrm{CHDI}$ Foundation/CHDI Management, Los Angeles, CA, USA

E-mail: glorioso@pitt.edu

\section{REFERENCES}

1 Paulsen JS. Early detection of Huntington disease. Future Neurol 2010; 5: 85-104.

2 Garriga-Canut M, Agustín-Pavón C, Herrmann F, Sánchez A, Dierssen M, Fillat C et al. Synthetic zinc finger repressors reduce mutant huntingtin expression in the brain of R6/2 mice. Proc Natl Acad Sci USA 2012; 109: E3136-E3145.

3 Zhang HS, Zeitler B, Froelich S, Yu Q, Pearl J, Paschon DE et al. Engineered zinc finger transcriptional repressors selectively inhibit mutant huntingtin expression and reverse disease phenotypes in Huntington's disease patient-derived neurons and in rodent models. Program No. 769.12. 2014 Neuroscience Meeting Planner. Washington, DC, USA: Society for Neuroscience, 2014. Online.

4 Vonsattel JP, Myers RH, Stevens TJ, Ferrante RJ, Bird ED, Richardson EP Jr. Neuropathological classification of Huntington's disease. I Neuropathol Exp Neurol 1985; 44: 559-577.

5 Vonsattel JP, DiFiglia M. Huntington disease. J Neuropathol Exp Neurol 1998; 57: 369-384.

6 Cisbani G, Cicchetti F. An in vitro perspective on the molecular mechanisms underlying mutant huntingtin protein toxicity. Cell Death Dis 2012; 3: e382.

7 Shao J, Diamond MI. Polyglutamine diseases: emerging concepts in pathogenesis and therapy. Hum Mol Genet 2007, 16 Spec No 2: R115-R123.

8 Reiner A, Albin RL, Anderson KD, D'Amato CJ, Penney JB, Young AB. Differential loss of striatal projection neurons in Huntington disease. Proc Natl Acad Sci USA 1988; 85: 5733-5737. 
9 Rosas HD, Salat DH, Lee SY, Zaleta AK, Hevelone N, Hersch SM. Complexity and heterogeneity: what drives the ever-changing brain in Huntington's disease? Ann NY Acad Sci 2008; 1147: 196-205.

10 Gil JM, Rego AC. Mechanisms of neurodegeneration in Huntington's disease. Eur J Neurosci 2008; 27: 2803-2820.

11 Zuccato C, Valenza M, Cattaneo E. Molecular mechanisms and potential therapeutical targets in Huntington's disease. Physiol Rev 2010; 90: 905-981.

12 Bithell A, Johnson R, Buckley NJ. Transcriptional dysregulation of coding and noncoding genes in cellular models of Huntington's disease. Biochem Soc Trans 2009; 37: 1270-1275.

13 Yano H, Baranov SV, Baranova OV, Kim J, Pan Y, Yablonska S et al. Inhibition of mitochondrial protein import by mutant huntingtin. Nat Neurosci 2014; 17: 822-831.

14 Rigamonti D, Bauer JH, De-Fraja C, Conti L, Sipione S, Sciorati C et al. Wild-type huntingtin protects from apoptosis upstream of caspase-3. J Neurosci 2000; 20: 3705-3713.

15 Kumar P, Kalonia H, Kumar A. Huntington's disease: pathogenesis to animal models. Pharmacol Rep 2010; 62: 1-14.

16 Ramaswamy S, McBride JL, Kordower JH. Animal models of Huntington's disease. ILAR J 2007; 48: 356-373.

17 Bemelmans AP, Horellou P, Pradier L, Brunet I, Colin P, Mallet J. Brain-derived neurotrophic factor-mediated protection of striatal neurons in an excitotoxic rat model of Huntington's disease, as demonstrated by adenoviral gene transfer. Hum Gene Ther 1999; 10: 2987-2997.

18 Huang B, Schiefer J, Sass C, Landwehrmeyer GB, Kosinski CM, Kochanek S. Highcapacity adenoviral vector-mediated reduction of huntingtin aggregate load in vitro and in vivo. Hum Gene Ther 2007; 18: 303-311.

19 Kells AP, Fong DM, Dragunow M, During MJ, Young D, Connor B. AAV-mediated gene delivery of BDNF or GDNF is neuroprotective in a model of Huntington disease. Mol Ther 2004; 9: 682-688.

20 McBride JL, During MJ, Wuu J, Chen EY, Leurgans SE, Kordower JH. Structural and functional neuroprotection in a rat model of Huntington's disease by viral gene transfer of GDNF. Exp Neurol 2003; 181: 213-223.

21 Ettinger MP, Littlejohn TW, Schwartz SL, Weiss SR, Mcllwain HH, Heymsfield SB et al. Recombinant variant of ciliary neurotrophic factor for weight loss in obese adults: a randomized, dose-ranging study. JAMA 2003; 289: 1826-1832.

22 Denovan-Wright EM, Attis M, Rodriguez-Lebron E, Mandel RJ. Sustained striatal ciliary neurotrophic factor expression negatively affects behavior and gene expression in normal and R6/1 mice. J Neurosci Res 2008; 86: 1748-1757.

23 Ramaswamy S, McBride JL, Han I, Berry-Kravis EM, Zhou L, Herzog CD et al. Intrastriatal CERE-120 (AAV-Neurturin) protects striatal and cortical neurons and delays motor deficits in a transgenic mouse model of Huntington's disease. Neurobiol Dis 2009; 34: 40-50.

24 McBride JL, Boudreau RL, Harper SQ, Staber PD, Monteys AM, Martins I et al. Artificial miRNAs mitigate shRNA-mediated toxicity in the brain: implications for the therapeutic development of RNAi. Proc Natl Acad Sci USA 2008; 105: 5868-5873.

25 Harper SQ, Staber PD, He X, Eliason SL, Martins IH, Mao Q et al. RNA interference improves motor and neuropathological abnormalities in a Huntington's disease mouse model. Proc Natl Acad Sci USA 2005; 102: 5820-5825.

26 Popovic N, Maingay M, Kirik D, Brundin P. Lentiviral gene delivery of GDNF into the striatum of R6/2 Huntington mice fails to attenuate behavioral and neuropathological changes. Exp Neurol 2005; 193: 65-74.

27 van Bilsen $\mathrm{PH}$, Jaspers $\mathrm{L}$, Lombardi MS, Odekerken JC, Burright EN, Kaemmerer WF. Identification and allele-specific silencing of the mutant huntingtin allele in
Huntington's disease patient-derived fibroblasts. Hum Gene Ther 2008; 19: 710-719.

28 Zhang Y, Engelman J, Friedlander RM. Allele-specific silencing of mutant Huntington's disease gene. J Neurochem 2009; 108: 82-90.

29 Lombardi MS, Jaspers L, Spronkmans C, Gellera C, Taroni F, Di Maria E et al. A majority of Huntington's disease patients may be treatable by individualized allele-specific RNA interference. Exp Neurol 2009; 217: 312-319.

30 Pfister EL, Kennington L, Straubhaar J, Wagh S, Liu W, DiFiglia M et al. Five siRNAs targeting three SNPs may provide therapy for three-quarters of Huntington's disease patients. Curr Biol 2009; 19: 774-778.

31 Miller TW, Zhou C, Gines S, MacDonald ME, Mazarakis ND, Bates GP et al. A human single-chain $\mathrm{Fv}$ intrabody preferentially targets amino-terminal Huntingtin's fragments in striatal models of Huntington's disease. Neurobiol Dis 2005; 19: 47-56.

32 Colby DW, Chu Y, Cassady JP, Duennwald M, Zazulak H, Webster JM et al. Potent inhibition of huntingtin aggregation and cytotoxicity by a disulfide bond-free single-domain intracellular antibody. Proc Natl Acad Sci USA 2004; 101: 17616-17621.

33 Zhang H, Yang B, Mu X, Ahmed SS, Su Q, He R et al. Several rAAV vectors efficiently cross the blood-brain barrier and transduce neurons and astrocytes in the neonatal mouse central nervous system. Mol Ther 2011; 19: 1440-1448.

34 Gray SJ, Kaibourgi SN, McGown TJ, Samulski RJ. Global CNS gene delivery and evasion of anti-AAV neutralizing antibodies by intrathecal AAV administration in non-human primates. Gene Ther 2013; 20: 450-459.

35 Salegio E, Samaranch L, Kells AP, Mittermeyer G, Sebastian WS, Zhou S et al. Axonal transport of adeno-associated viral vectors is serotype-dependent. Gene Ther 2013; 20: 348-352.

36 San Sebastian W, Samaranch L, Heller G, Kells AP, Bringas J, Pivirotto P et al. Adeno-associated virus type 6 is retrogradely transported in the non-human primate brain. Gene Ther 2013; 20: 1178-1183.

37 Kells AP, Hadaczek P, Yin D, Bringas J, Varenika V, Forsayeth J et al. Efficient gene therapy-based method for the delivery of therapeutics to primate cortex. Proc Natl Acad Sci USA 2009; 106: 2407-2411.

38 Cairns TM, Huang ZY, Gallagher JR, Lin Y, Lou H, Whitbeck JC et al. Patient-specific neutralizing antibody responses to herpes simple virus are attributed to epitopes on gD, gB or both and can be type specific. J Virol. 2015; 89: 9213-9231.

39 Richardson RM, Kells AP, Rosenbluth KH, Salegio EA, Fiandaca MS, Larson PS et al. Interventional MRI-guided putaminal delivery of AAV2-GDNF for a planned clinical trial in Parkinson's disease. Mol Ther 2011; 19: 1048-1057.

40 Miyagawa Y, Marino P, Verlengia G, Uchida H, Goins WF, Yokota S et al. Herpes simplex viral vector design for efficient transduction of non-neuronal cells without cytotoxicity. Proc Natl Acad Sci USA 2015; 112: E1632-E1641.

41 Mazzacurati L, Marzulli M, Reinhart B, Miyagawa Y, Uchida H, Goins WF et al. Use of miRNA response sequences to block off-target replication and increase the safety of an unattenuated, glioblastoma-targeted oncolytic HSV. Mol Ther 2014; 23: 99-107.

42 Fanara P, Wong PY, Husted KH, Liu VM, Kohlstaedt LA, Riiff T et al. Cerebrospinal fluid-based kinetic biomarkers of axonal transport in monitoring neurodegeneration. J Clin Invest 2012; 122: 3159-3169.

43 Sturrock A, Laule C, Wyper K, Milner RA, Decolongon J, Dar Santos R et al. A longitudinal study of magnetic resonance spectroscopy Huntington's disease biomarkers. Mov Disord 2015; 30: 393-401.

44 Feigin A, Leenders KL, Moeller JR, Missimer J, Kuenig G, Spetsieris P et al. Metabolic network abnormalities in early Huntington's disease: an [(18)F]FDG PET study. J Nucl Med 2001; 42: 1591-1595. 